\title{
Pre-service Teachers' Opinion about Inquiry-Based Learning Through Kindergarten Space
}

\author{
Marina Sounoglou ${ }^{1, *}$ \\ ${ }^{1}$ School of Humanities and Social Sciences, Dept. of Preschool Education, University of \\ Thessaly, Argonafton \& Filllelinon, Volos, 38221, Greece \\ *Corresponding author: School of Humanities and Social Sciences, Dept. of Preschool \\ Education, University of Thessaly, Argonafton \& Filllelinon, Volos, 38221, Greece. Tel: \\ 30-697-972-0622. E-mail: masounoglou@ece.uth.gr
}

Received: September 12, 2019 Accepted: September 21, 2019 Published: September 25, 2019

doi:10.5296/ije.v11i3.15432 URL: https://doi.org/10.5296/ije.v11i3.15432

\begin{abstract}
The research process is a safe way for children to learn. The inquiry-based learning in kindergarten enables children to deepen their knowledge and expand it on existing ones. The kindergarten space contributes to it depending on its layout and how it is utilized of them. The methodology that used was the qualitative discourse analysis in the submitted minutes of students' activities and evaluations coded for the concept of inquiry-based learning. The research sample consists of the texts of 159 pre-service teachers from the School of Preschool Education of the University of Thessaly. The results make it clear that, based on the research questions posed in the present study, pre-service teachers believe that inquiry-based learning can be cultivated in relation to the way that the space is shaped.
\end{abstract}

Keywords: pre-service teacher, inquiry-based learning, kindergarten space 


\section{Introduction}

The issue of the environment in early childhood has engaged intellectuals and educators, such as Froebel, Montessori, Piaget, Vygotsky, and Bronfenbrenner (Inan, 2009). Bruner, Werner, and Piaget have shown that cognitive development is based on sensory-kinetic activity in the environment, and evolves into symbolic coding and later into abstract thinking. Lynch argues that there is a correlation between the stages of cognitive development with the stages of understanding the macro environment. According to Lynch, forms of perception are elements of an evolutionary process through which the child learns about and orientates his or her

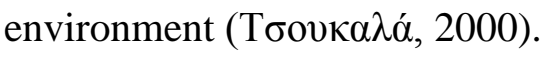

For this reason, Burnette proposes the notion of a "nesting place", a child-scale space that narrows its field of vision, to provide a solid background in which to visualize its action patterns. This delimitation of the sensory motor field of action helps him to concentrate on a

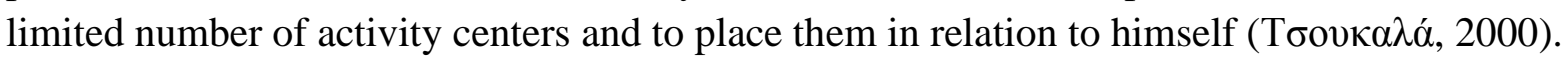

In 1966, Alfred Roth, an architect and school architecture expert, defined flexibility "as the ability of the space to be transformed without construction work and to be a tool for the teacher, who would use it according to the system he applies at all times." (Mannion, 2003)

\section{Inquiry-Based Learning}

Inquiry-based learning aspires to engage students in an authentic scientific discovery process (Pedaste et al., 2015). Inquiry-based learning based on the children questions. It is important children have personal involvement and avoid the passive energy of teacher. The framework should be suitable for learning due to the curiosity of children and an innate need of observe and explore the world (Michalopoulou, 2014). They learning in a various ways and this is a challenge for teachers to have an environment which promote the interests of children. Inquiry-based learning, or learning through small research, aims to create a learning environment that encourages students to seek information about a question or problem they are interested in, as well as to conduct research, or small research, to find answers to a question or problem. The questions may emerge from students to students or to teachers or from teachers to students.

Inquiry-based learning is a learning process through the questions generated by the students' interests, curiosity, and different perspectives / experiences. Children learn best when they are at the center of their own learning. When research is developed from the questions, curiosity and experiences of children, learning becomes an organic and motivating process that is truly enjoyable.

An important element in inquiry-based learning is the active involvement of children. In the research of Khan \& O'Rourke (2004) a key determinant of the inquiry-based learning is the active involvement with a complex problem or scenario, which is quite open, to allow a variety of responses and solutions from children.

In research of Minner, Levy \& Century's (2009) the active involvement of learners in the inquiry-based process takes place at four levels: (a) the level of involvement; (b) the level of learners' responsibility for learning; (c) the level of active thinking; and (d) the level of 
motivation.

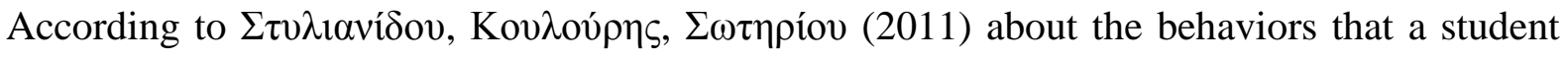
should develop in a classroom focused on inquiry-based learning and enriching them, we can say that children's active involvement also refers to the development of verbal interaction through formulating questions and taking risks, designing, formulating explanations based on data, the evaluation, self-assessment and creative thinking.

\section{Teachers Views about Inquiry-Based Learning}

In the research of Welch et al (1981) identify several reasons that teachers do not use the inquiry-based approach, citing the limited preparation of teachers, lack of time and space, the limited available materials, lack of support, the emphasis only on the content and difficulty in the application of inquiry-based teaching.

Then, according to research of Appleton (2002) argues that teachers' limited experience in exploratory approaches hampers the application of research to educational reality. In Barrett \& Zhang (2016) research the participants rated questions about what made for a 'comfortable built environment' and a 'well-functioning spaces', while the researchers examined and compared the spaces and spoke to the heads and to the pupils. Although overall teachers rate their schools only 'adequate'.

\section{The Space as a Parameter in Inquiry-Based Learning}

The kindergarten space is a crucial factor in the pedagogical process in its daily practice. It's not just the environment that hosts the process of learning. The dynamics that developed between the space and its users, it has emerged as an important factor in the pedagogical process. It should also be noted that the structured space of the kindergarten, like any other building, helps the child to acquire concepts, skills and attitudes related to the natural

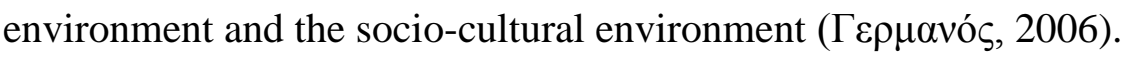

The classroom is a pedagogical tool by which the educator can extend the learning process. Properly designed space, which will be flexibly designed by the educator to suit the needs of the children so that its usability is not unambiguous, is a factor contributing to learning. Proper design gives children the opportunity to choose according to their interests and desires the content and area of activity in which they want to get involved. Shaping such conditions

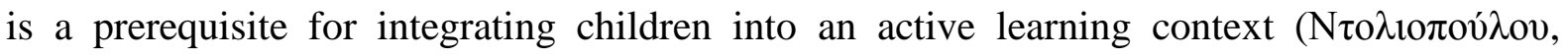
2003).

Space stimuli have a threefold utility. First of all provide information to the child that is relevant about the world and the phenomena surrounding it, about the content of the syllabus and about the child's own interests. Furthermore, cultivate the child's sensitivity and indirectly pave the way for aesthetic and cultural maturity. Also, provide the child with opportunities and directions for developing activities.

Research has shown that the environment in which the child operates can play a key role in 
attracting and developing attention, as there are environmental factors that can minimize or even interrupt the child's concentration period.

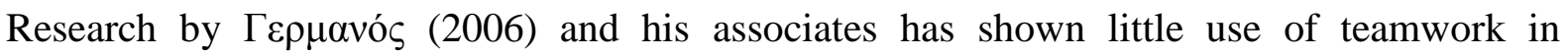
kindergarten, as its true meaning departs from the usual "day-to-day painting" pattern. The collaborative learning method presupposes the activity, the intervention in the space, the shaping, the subversion of both the activity and the space that will host it.

In a documented study, American psychologist Carol Weinstein demonstrates the preschooler's active relationship with space, and points out that restriction on the use of space can mitigate the positive effects on the development of a child's cognitive and emotional

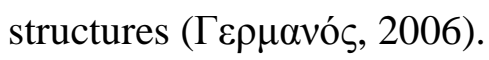

\section{Research}

\subsection{Research Scope}

Based on the aforementioned, it is researched in the texts of the prospective teachers to the extent that the layout and organization of the kindergarten space promotes the inquiry-based learning.

\subsection{Research Sample}

The research sample consists of the texts of 159 from the 2nd year teacher educators in the School of Preschool Education of the University of Thessaly during the academic year 2018 2019.

\subsection{Research Inquires}

Based on the above, the research questions that arise are the following:

Q1: How did pre-service teachers conceive of the concept of inquiry-based learning and how it can be cultivated in the kindergarten?

Q2. Is there a difference between teams and team members for the inquiry-based learning in kindergarten space?

\subsection{Research Methodology}

The methodology that used was the qualitative discourse analysis in the submitted minutes of students' activities and evaluations coded for the concept of inquiry-based learning. The method used is interpretive-qualitative content analysis, which is considered the most appropriate research method in analyzing texts (Stemler, 2001). Content analysis is a method suitable for the analysis of verbal, oral and written data (Mayring, 2000) and for deepening into a text containing a large amount of information (Fairclough, 1995). Emphasis is placed on important points of the text, which are organized into categories according to their content. This has the effect of facilitating the study and interpretation of texts but also of drawing easier conclusions (Stemler, 2001). For the purpose of analyzing and comparing texts and 
presenting them, focused on the concept of "inquiry-based learning" and the elements that support it.

\section{Results}

The analysis of the texts revealed that the pre-service teachers believe that the kindergarten space can be a factor for the development of inquiry-based learning. The following categories emerged are tree, the space, the material and the interaction.

\subsection{Space}

Through the organization of the space, questions and ideas are born and this is done effortlessly. The space when cornered, or otherwise, can be better utilized by students. In terms of space organization, flexibility and the use of stimuli and landmarks from the fantasy world allow for frequent changes that can lead to the formation of appropriate microenvironments.

Children share and exchange their thoughts, so that the compulsory nature of education is not promoted. In addition, the discussion gives birth to ideas and questions that the child had not previously encountered. However, the pedagogical corner also provides such opportunities where the learner comes into contact with learning on his or her own initiative $(X 1)$.

This space provides inquiry-based learning opportunities if we consider that every corner is organized for this purpose, so children throughout the kindergarten are constantly exploring and questioning. For example, the reading corner with the various books in their library provides knowledge, information and thoughts. (X2)

Actively mobilizes toddlers through the corner of building materials, where children sharpen their minds to create constructions (X12)

By creating all of these varied corners it aims at broader learning in infants. Toddlers through the corner of painting they can learn better to imprint on the paper what they see, while enhancing their more artistic side. The painting sharpens the imagination. The table games are a good helper for strategy as children learn the rules of play accordingly, enhancing teamwork. The corner of the book is not intended to enrich or teach vocabulary to toddlers, however, through the storytelling of toddlers aiming to hear and see images fantastically shaped by the fairy tale (X13).

Mainly in the corner of the friendship where the toddlers sit and talk about topical issues together (X17)

We believe that it provides opportunities for inquiry-based learning as primarily the environment corner. Children could explore the nature and through it learned to plant plants. (X18)

The kindergarten teachers had placed colored sheets (green, red, orange) on the ceiling that 
encouraged the children to create in their imagination that they were in a magical forest, with beautiful colors in the sky. Then the children were move their hands as if they were birds or butterflies and seeing them gave us the feeling of something dreamy and fairy tale. Above the corner of the music the teachers had created a tree-shaped ceiling made of real tree branch and colored cardboards with red and orange leaves that gave the shape of an autumnal image (X30)

From the point of the use of the space, the ability of children to intervene and adapt it to their own centers of interest is an important prerequisite for exploratory learning. The school space is flexible when its layout and aesthetics can be exploited in many alternative ways (mainly thanks to the possibility of applying alternatives to furniture) to incorporate forms of educational interactions and emerging practices into the classroom were not foreseen.

The organization of the kindergarten provides opportunities for inquiry-based learning and mainly in the area of observation. In which there is a bulletin board in which the kindergartener occasionally places various objects that the children observe with the magnifying glass, touch them, talk to each other, and then paint according to what they feel and understood about the particular object (X41).

The organization of the class allowed all children to see their classmates and the kindergarten teacher so that they could discuss in a group and exchange views (X47).

The lending library corner allows children to browse and view various books, creating questions and getting them to look for pictures in the book or even in the classroom. The corner of the supermarket with various fruits and foods gives children the impetus to notice the shapes, colors and textures of the products. In the office, they can also search through, post, where they need to fill in the date or time, but also through the map to search, think and discuss (X49).

Through the corner of the computer (searching the Internet) and mathematics (through playing with arithmetic games. There was a general spirit of cooperation between the children. In the corner of the bricks they made various constructions in groups, on the benches they read fairy tales, and in the corner of the masquerades they made whole representations ("queen's breakfast") using kitchen and other toys (X51).

At the two tables in the corridor the children have created their own museum where they exhibit their collections with specific themes, such as autumn themed paintings. Although this place is out of order, this organization gives children an opportunity to show their collection to parents easily and quickly (X52).

Through the corner of the fairy tale, children enter a magical world by leafing through the story and thus creating the curiosity to actually explore this world. The computer in the classroom also contains various learning programs that allow the child to enrich their knowledge. Finally, the easel used as an exhibit helps children discover the world of art (X53).

Children learn new things every day from the corners, ask questions and look for something 
new each time. Everyone could offer exploratory learning, as it gives the child an incentive or a basis to become as creative as he or she wants (X54).

Alternative use of corners fosters exploratory learning. From the point of view of the use of space, the child should be able to intervene, alone or in groups, with or without the cooperation of the teacher, in the aesthetics and identity of their space and adapt it to their own centers of interest. These interventions must be done in a collaborative manner.

Each corner allows children to play with each other, so they learn in teamwork and collaboration and through the game and the different activities they learn from each other and exchange different information and knowledge. As they develop, they lead to more complex and complex forms of interaction with peers and adults that affect their linguistic and cognitive abilities (X32).

Some kids put wooden letters in the row and asked, "Mrs..., what word did we make?". Below the salon corner that was essentially a chair in front of a mirror and a small table with paraphernalia beyond the classic game will be played two children used the chair as a driver's seat and counted kilometers and practiced the right turn left asking the lady 'Mrs... which is left? "(CH57)

\subsection{Items - Materials}

The selection and suitability of materials are important factors for the development of inquiry-based learning.

Plenty of objects and materials kids create their own toys leaving their imagination free. In particular, while we were there, toddlers used bricks and made musical instruments (X8).

Through the corners, children are given the opportunity to create as well as research through the classroom material hanging around the classroom (X5).

Inquiry-based learning is provided to children through pictures, pictures, educational content posters in the classroom (X11).

The children were curious to learn about nature not only through the ability to plant their own plants but also from the queries and from the chat they came up with many topical issues. They learn about sounds, interact with the book, learn mathematics and apply them to the store (X18).

Various possibilities offered through games and various educational and recreational processes, from kindergarten to children (X24).

Given a possibility for children to experiment with the materials, the colors, puzzles, building material, make hypotheses, verifications, modifications, puzzled, reflecting upon, to draw conclusions taking their own decisions (X28).

The interest of children in getting to know the world is the motivation for learning. In a safe and stimulating rich environment, children explore with the senses, generate ideas and structure knowledge. At the same time, they are constantly using their knowledge and ideas 
for different purposes and in many ways. Thus, they develop their ability to adapt to the environment. Various questions and discussions arise when designing the curriculum that enhances learning. The 'learning game' also contributes to exploratory learning. Finally, through the organization of space, there was a discussion between students and kindergartener. In this way, questions and unknown words are described in various ways (X32).

Knowledge games, like maps, play an essential role in children's cognitive development and learning because they provide stimuli for observation, experimentation, question generation, understanding and problem solving (X42)

The alternative way of using objects is the basis of inquiry-based learning. Children use objects not only for their intended use but also for other uses in their play.

We give opportunities to children in order to explore and learn from the objects in the space. We observe that every child uses a simple bench in the room for a different reason and in a different way. For example, this simple bench can be used for a bed, a seat, or even a pedestal (X45).

I support this because in the corner of the library, the child, after flipping through some pictures, can compare some of them to reflect and wonder effectively asking the kindergartener. Also in the corner of the building material where there are several puzzles, the toddler uses his imagination but at the same time tries to find out which pieces are related to which, observing and thinking, a little research through his various attempts. Thus he develops his exploratory learning (X48).

\subsection{Interaction}

\subsubsection{Interaction among children}

The organization enables interaction and conversation to exchange ideas and opinions among children.

The specific organization of the room enables interaction and cooperation between the children and their classmates. The way the room is organized gives the space a functionality through which children can move and move various toys in order to, through their collaboration with other classmates, develop a story - a game. The "corner of visual arts" but also the "corner of building materials" serve this purpose. There the children cooperate more easily because of the material provided (X3).

The chairs are next to each other, thus allowing them to talk to each other and to exchange ideas and opinions (X8).

Coexistence in groups because of corners develops children socio-emotional and promotes creativity and cooperation (X12)

The opportunities that space provides for interaction with the environment can lead to skills acquisition and behavioral modifications. Space is a field of activities in which the child thinks, acts, plays, communicates, and interacts, forming places, especially during his or her 


\section{Macrothink}

play.

Toddlers play, communicate, and interact, which can be considered a focal point in a child's life because it is the first time they interact with a place with so many children and learn to share (X13)

\subsubsection{Interaction between children and the teacher}

The kindergarten teacher can contribute to exploratory learning with the help of children ex. Query resolution (X9)

Inquiry-based learning is possible as there are various possibilities offered through games and various educational and recreational processes, from kindergarten to children (X24).

Children could get involved on their own, but always with the help and advice of the teacher, so that they could learn things and solve their questions (X25).

The layout, the aesthetics and the way the classroom is used contribute to the design of educational sites in the classroom and enhance educational communication and interaction

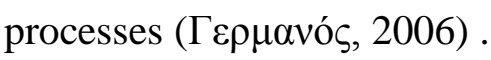

For example kids drew the peace sign, on the occasion of the National Holiday, and through questions and discussion analyzed the importance and the difference between peace and war (X46).

The kindergarten encouraged the children to express themselves freely and create their own toys and promoted all the ideas of the children without criticizing them (X47).

It is essential to be together and to discuss different issues with each other and with their kindergarten teacher. Through these discussions, they are given the opportunity to express their queries, ideas, views and knowledge they already have, thereby discovering answers and enriching existing knowledge (X50).

The layout of the space and the well-organized classroom favors the development of dialogue as a form of communication and cooperation as a form of interaction.

Their teacher was quite encouraging in what the children did (X56).

Flexibility allows the development of many different forms of educational communication and interaction that facilitate the alternation of teaching approaches.

The teacher takes care to make deepening in children or bringing them together in the middle of the class explaining things or going to the corner of the library or at the computer corner where the direction of the children explore and indulge on the subject through the use of the Internet and thus conducting exploratory learning (X58).

\subsection{The Space as a Hindrance}

However, there are times when organizing the space and interacting to foster exploratory learning can be a hindrance. 
This organization does not provide many opportunities for exploratory learning. On the contrary, it reinforces teacher-centered teaching and motif, the teacher asks and the child responds. In the corner of friendship the teacher is at the top of the circle a short distance from the students, and the seat is at the beginning of the classroom "overseeing" the corners (X16).

However the space was extremely organized and each object had its own place in the space. There was no opportunity to modify existing furniture and turn it into something completely different that would give new prospects for child employment (X18).

The way the kindergarten is organized does not allow the children to discover something new. There may be several angles but it is not as if we have given the child something ready without giving them room to explore. (X27)

The material available is one-dimensional and children are adjusted to this data. Still missing corners that will enrich thematically a project such as theatrical play, the music corner where they could approach a subject from many corners. The organization may not provide opportunities for inquiry-based learning, as children depending on the angles are limited in their movements. Therefore, since they do not have the opportunity to move freely in space, they do not have the opportunity to discover all their potential and learn new data for themselves and for the world (X35).

From the 159 pre-service teachers who participated in the survey, 30 of them replied that the space does not provide inquiry-based learning opportunities, as there were no appropriate spaces or corners in this case with the necessary tools.

There are no particular opportunities for exploratory learning. There is guidance from kindergarten teacher. (X72)

No, the organization does not provide opportunities for exploratory learning. The material is given from kindergartener and there is no creativity (X69).

\section{Discussion}

The results make it clear that, based on the research questions posed in the present study, pre-service teachers believe that inquiry-based learning can be cultivated in relation to the way that the space is shaped. More specifically, through the arrangement of the space, the selection of appropriate educational material and at the same time the interaction of the pupils with each other and with the teacher.

The development of exploratory learning is a complex issue for the teacher to anticipate and exploit in the area of children's education and benefits in enhancing both collective and individual development at all levels of cognitive, social and emotional levels.

Finally, no differences were found between the groups and between the members of the groups regarding the possibility of developing inquiry-based learning. Pre-service teachers consider that the space is a catalyst that enhances and promotes inquiry-based learning. 
The space organization, the flexibility and the use of stimuli and landmarks from the fantasy world allow the children for frequent changes. Also, the organization of space supports the notion that outdoor, inquiry-based learning can be one way to engage students in their own knowledge construction (MacDonald, 2016). Furthermore, the selection and suitability of materials are important factors for the development of inquiry-based learning. The inquiry-based methodology can be perfectly applied in the Early Years (Caballero \& Diaz, 2018). The organization of space enables interaction and conversation to exchange ideas and opinions among children and teacher. Children can develop investigative and analytic strategies, at the same time that they improved their social and communicative skills (Harwood et al., 2015). They can develop abilities such as problem-posing and building arguments and negotiations (Abd-El-Khalick et al., 2015).

\section{Suggestions}

The school environment has been aptly described as "the third teacher". So, it should be rich in visual stimuli and providing material for children's creations. The kindergarten contributes to all areas of children's development as it facilitates the connection of their actions with "real" life. Children are free to act and create activities with real tools and materials. They are capable of action, interaction and creation, in a diverse and multi-factor environment. The role of the teacher is to provide a space with safety, time and comfort and to encourage the children to carry out their research in depth (Inan, 2009).

Given that the kindergarten classroom space must be flexible and easily adaptable to the needs of each activity and children, a clear and independent form is given to each area and its functions. Teachers should focus on inquiry and integrate it into their daily teaching practices, promoting out-of-school learning (Caballero \& Diaz, 2018). The programs and curriculum should give the teachers the opportunity to develop themselves professionally. This can be through education and adequate training in the fundamental issue of integrating inquiry into their curriculum design to make it more effective for learning and to promote the education of out-of-school students.

In order to teachers be able to foster exploratory learning, it is important to understand and clarify the process of inquiry-based learning. Therefore, it is obvious that modern teaching trends need to shift in the direction of inquiry. Teachers, therefore, it is good to be trained and to acquire knowledge and concerning the application of exploration on teaching concepts and practices in the classroom, in order to support learners' sense of choice, wonder, and delight.

\section{References}

Abd-El-Khalick, F., Lederman, N., \& Schwartz, R. (2015). Inquiry, as a curriculum strand. In: Gunstone R. (eds) Encyclopedia of Science Education. Springer, Dordrecht. pp. 510-514. https://doi.org/10.1007/978-94-007-2150-0_190

Appleton, K. (2002). Science Activities That Work: Perceptions of Primary School Teachers, 


\section{Macrothink}

International Journal of Education ISSN 1948-5476 2019, Vol. 11, No. 3
Research
Science
Education.
$32(3)$,
393-410.

https://doi.org/10.1023/A:1020878121184

Barrett, P., Barrett, L., \& Zhang, Y. (2016). Teachers' views of their primary school classrooms. Intelligent Buildings International. 8(3), 176-191.

Caballero G., \& Diaz R. (2018). Inquiry-Based Learning: an Innovative Proposal for Early Childhood Education. Journal of Learning Styles, 11(22), 50-81.

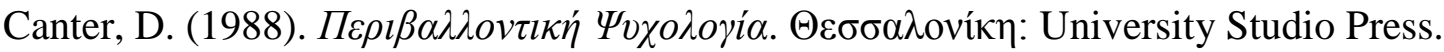

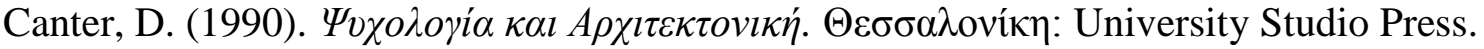

Fairclough, N. (1995). Critical discourse analysis. London: Longman.

Harwood, D., Bajovic, M., Woloshyn, V., Di Cesare, D., Lane, L., \& Scott, K. (2015). Intersecting Spaces in Early Childhood Education: Inquiry-Based Pedagogy and Tablets. The International Journal of Holistic Early Learning and Development, 1, 53-67.

Inan, H. (2009). Understanding features of amiable environments that can nourish emergent literacy skills of preschoolers. Australian Journal of Basic and Applied Sciences, 3(3), 2510-2518.

Khan, P. O'Rourke, K. (2004). Guide to Curriculum Design: Enquiry-based Learning. Generic Centre, Higher Education Academy. Retrieved from http://www.ceebl.manchester.ac.uk/resources/guides/kahn_2004.pdf

MacDonald, K. (2016). Back to the Garten: Inquiry-Based Learning in an Outdoor Kindergarten Classroom. St. Catherines, Ontario: Brock University. Retrieved from https://dr.library.brocku.ca/bitstream/handle/10464/9325/Brock_MacDonal\%20d_Kate_ 2016.pdf? sequence $=1 \&$ is Allowed $=y$

Mannion, G. (2003). Children's participation in school grounds developments:creating a place for education that promotes children's social inclusion. International. Journal of Inclusive Education, 7(2), 172-192.

Mayring, P. (2000). Qualitative Content Analysis, Forum Qualitative Social Research, 1(2). Retrieved from http://www.qualitative-research.net/index.php/fqs/article/view/1089/2385

Michalopoulou, A. (2014). Inquiry-Based Learning through the Creative Thinking and Expression in Early Years Education. Creative Education, 5(6), 377-385. http://dx.doi.org/10.4236/ce.2014.56047

Minner, D., Levy, A., Century, J. (2010). Inquiry-based science instruction-What is it and does it matter? Results from a research synthesis years 1984 to 2002. Journal of Research in Science Teaching, 47(4), 474-496. https://doi.org/10.1002/tea.20347

Pedaste, M., Mäeots, M., Siiman, L. A., de Jong, T., van Riesen, S. A. N., Kamp, E. T., et al. (2015). Phases of inquiry-based learning: Definitions and the inquiry cycle. Educational 
Research Review, 14(1), 47-61. https://doi.org/10.1016/j.edurev.2015.02.003

Stemler, S. (2001). An overview of content analysis. Practical Assessment, Research \& Evaluation, 7(17). Retrieved from http://PAREonline.net/getvn.asp?v=7\&n=17

Welch, W., Klopfer, L., Aikenhead, G., Robinson, G. (1981). The role of inquiry in science education: Analysis \& recommendations. Science Education, 65(1), 33-50. https://doi.org/10.1002/sce.3730650106

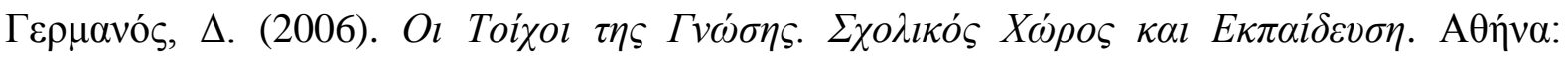
Gutenberg.

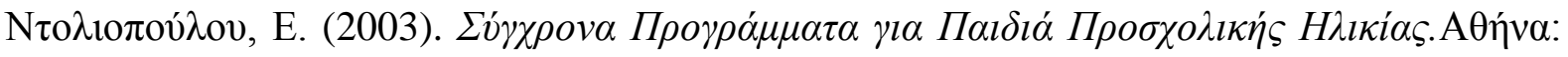
Тv $\omega \omega \theta \dot{\tau} \tau \omega$.

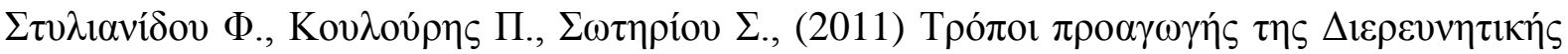

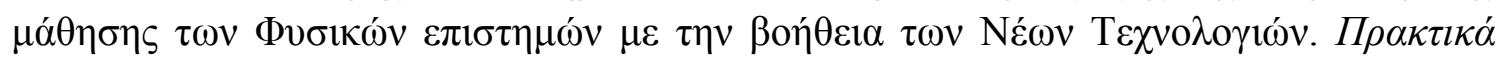

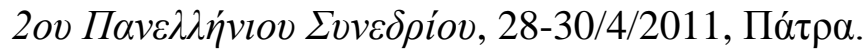

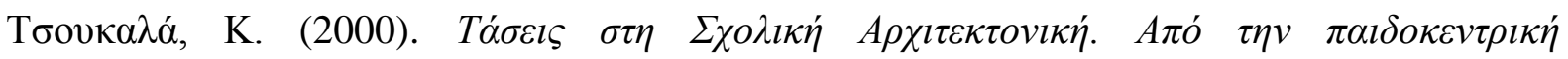

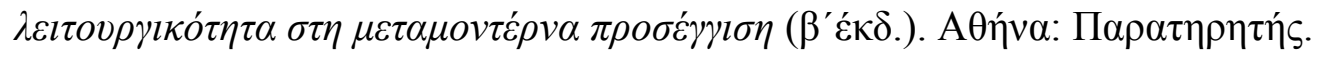

\section{Copyright Disclaimer}

Copyright for this article is retained by the author(s), with first publication rights granted to the journal.

This is an open-access article distributed under the terms and conditions of the Creative Commons Attribution license (http://creativecommons.org/licenses/by/3.0/). 